\title{
A Unified Fashion Technology in Trends of Textile Engineering Science 7000Bc in Egypt
}

\author{
Elsayed Ahmed Elnashar* \\ Faculty of Specific Education, Kafrelsheikh University, Egypt
}

*Corresponding author: Elsayed Ahmed Elnashar, Full-Professor of textiles \& Apparel, Faculty of Specific Education, Kaferelsheikh University, Egypt

Submission: 眥 February 26, 2018; Published: 㘹 March 19, 2018

\section{Editorial}

A unified fashion technology in the textile industry is one of the oldest in the world. The oldest known textiles, which date back to about 5000B.C. are scraps of linen cloth found in Egyptian caves. The industry was primarily a family and domestic one until the early part of the 1500s when the first factory system was established. One important difference between ancient Egyptian and Western aesthetics is that, in the former, there has been little if any critical discourse on art and beauty until very recently. Which can be taken as representative of various heterodox ancient Egyptian traditions after the fifteenth century, whether the middle Kingdom (c.20401640 BC) at Bani Hasan in middle Egypt. The earliest example is the tiny ivory statuette of an unknown First-Dynasty King (C.29292770 BC) from Abydos and now in the British Museum .the traditional view that sculpture and painting with textures of stretch fabrics is $3 \mathrm{D}$ and painting $2 \mathrm{D}$.
Unifying fitting-form of stretch fabric of ancient Egyptian, the systems designed to acquire the motion of points on a flexiblemoving surface such as cloth. Historical research has uncovered ancient Egyptian formulae for many conditions of which the aesthetical of stretch fabric, the reduction of stretch wrinkling, and there were in circulation at that time recipes for facilitating hair growth and getting rid of stretch clothes. And artists and sculptors and painting as Figures $1(\mathrm{a}, \mathrm{b} \& \mathrm{c})$, were interested in fabric draping qualities. But also to their clothes of women being massaged with sexual dressed of stretch fabric and in fine linens, and garlanded with flowers are commonly depicted in the art of the time. The famous loom in Chnem Hotep`s tomb at Bani Hasan appear vertical, Contemporary tomb models like that of MekhetRe (C.2020BC) from Deir-el-Bahri clearly show horizontal loom, as well as spinning, plying and warping, the latter done by stretching warp-threads over pegs driven into a wall.

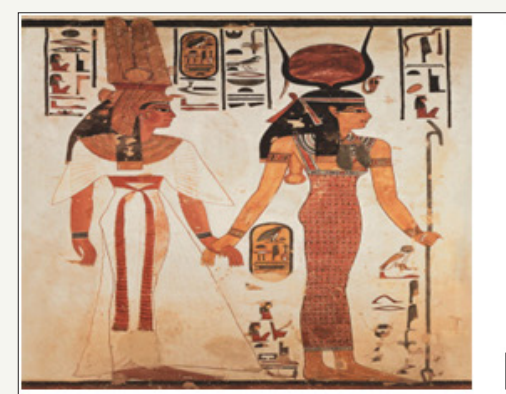

(a)
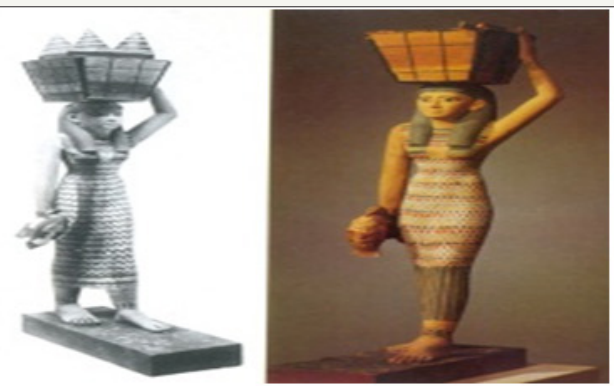

(b)

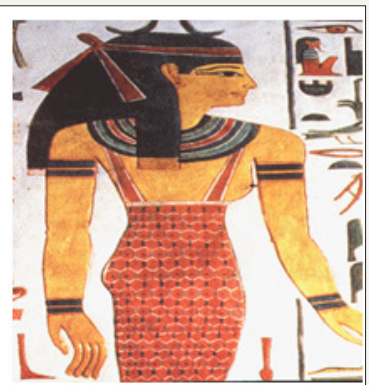

(c)

Figure 1 : Illustrates 3-D energy cloth stretch dress at sculpture (Egyptian artpp116).

This illustration is part of an ivory chest, which is about $31 / 2$ thousand years old. It is decorated in a carved relief of a garden promenade of Tutankhamen and his wife Anch-es-Amun.

A unified stretch theory of ancient clothes of seamless technology makes it possible that yarn is directly made into apparel without any cutting and sewing trends of textile engineering science $7000 \mathrm{Bc}$ in Egypt. Because of the seamless in the neck, waist, hip and other parts, customers can enjoy much more the advantages such as comfort, fitness, fashion and change of shape stretch theory of ancient clothes. Seamless garment is a kind of one-time forming clothes produced by seamless knitting machine. Seamless technology makes it possible that yarn is directly made into apparel without any cutting and sewing. Because of the seamless in the neck, waist, hip and other parts, customers can enjoy much more the advantages such as comfort, fitness, fashion and change of shape stretch theory of ancient clothes. The sewing process may create needle hole on the sewn product that reduce the 
marketability and also the stress created at the seam portion will also leads to premature failure in the garment. Cutting and sewing is a labor intensive process which creates the human error, and then the cutting process creates more fabric wastages. Seamless is trendy and techie fashion garment knitting stretch theory of ancient clothes on the V-bed machine has primarily been used for apparel. However, in recent years, this new trendy and techie fashion of three-dimensional knitting technique has been extended in other areas such as fashion, upholstery, industrial, automotive and medical textiles.

A unified stretch theory of ancient clothes of seamless garment is a kind of one-time forming clothes produced by seamless knitting machine. In the existing production system the cutting and sewing process is mostly labor oriented. The sewing process may create needle hole on the sewn product and also the stress created at the seam portion. Process which creates the human error, seamless trendy and techie fashion are garment technology is advancement in apparel industry which eliminates the fabric laying, cutting and sewing process. In addition to that seamless garment gives more comfort. Circular knitting machines Trendy and Techie Fashion were used for making seamless garment in earlier days. Stretch Potential theory of ancient clothes technology is the best gift that man can have various technological innovations have changed the face of the world all together. Man is doing as little work as possible and reaping the best benefits out of his efforts. No industry has remained untouched! Stretch potential Technology has touched all the sectors and areas. Stretch potential theory of ancient clothes fashion industry could not have been left behind either. Creativity and technology makes exquisite fashion possible for men and women clothe. Trendy and techie fashion exquisite garments to cover a body are available in the market Production is the produced value in the simplest sense. Trendy and techie fashion in order to realize profitable growth, firms have to manufacture products valuable for consumers, increase their incomes, reduce costs, improve procurement period and increase consumer satisfaction. It protects him from the fluctuating weather and also adds to his visual appeal. Trendy and techie fashion the clothes in modern times serve various purposes in addition to covering a bare body. For example, there are clothes that are stain resistant, water repellent, antibacterial, of innumerable patterns and designs, etc. Clothes have become functional and attractive.

Trendy and techie technological innovations in the textile industry make this change possible. Technologies that have never been heard of before keep cropping up in the market, every now and then! For example, 3 Dimensional (3D) technology is the most talked about of all technologies in the textile software industry. It lets manufacturers to view how a design looks like on an individual virtually, even before the garment is actually created. Trendy and techie nanotechnology is the most popular technology in modern times. It is an advanced technology used in textile machineries to give required properties to the manufactured fabrics. Particles are manipulated at a nano level to make a sheet that has the desired properties. This sheet consisting of desired properties are attached to the piece of garment. Advanced textile machineries come equipped with this technology. It lets people wear clothes that will cover their body and also perform other functions. Trendy and techie nanotechnology in textile and colouring walls were found in Egyptian caves. The fundamentals of nanotechnology lie in the fact that the properties of materials drastically change when their dimensions are reduced to manometer scale. Nowadays also the textile industry has discovered the possibilities of nanotechnology. So, we can define nanotechnology in textile as the understanding throw engineering science $7000 \mathrm{Bc}$ in Egypt. Application of armour industry since seven thousand years BC, since the days of the Pharaohs in Egypt, we have monitored the developments of the armour industry. The driving force of z-yarn elastic properties behind the research in the area of 3D architecture multilayer composites from sustainable materials is to develop new structures from advanced and with natural resources that are environmentally friendly to overcome the negative impact of current composites. This paper describes recent armour advancements in one of the fastest growing areas of modern composite materials thick unitary composites manufactured from the 3D woven single layer performs as shown in Figure 2.

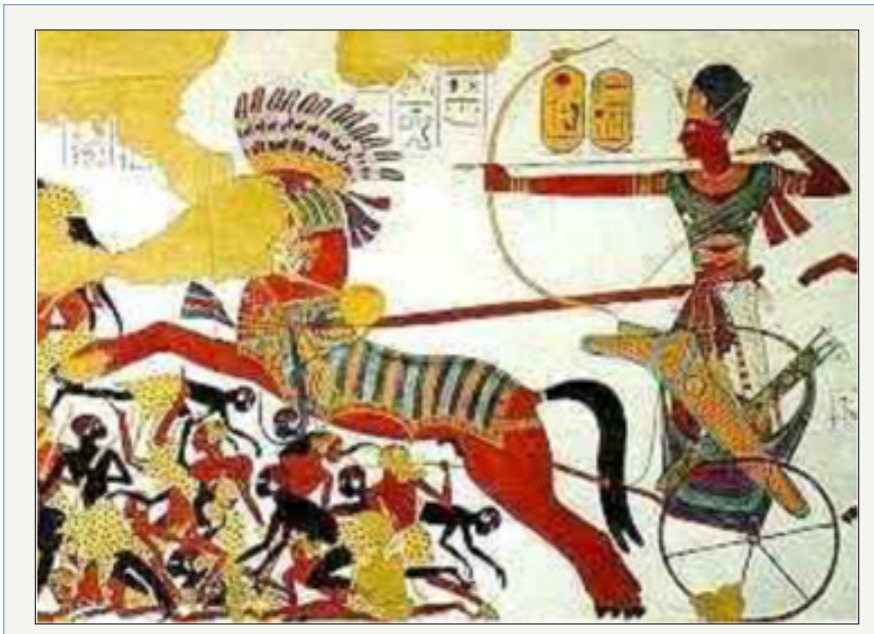

Figure 2 

(c) (†) Creative Commons Attribution 4.0

For possible submissions Click Here

Submit Article
TTEFT $\mid$

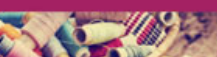

Trends in Textile Engineering \& Fashion Technology

\section{Benefits of Publishing with us}

- High-level peer review and editorial services

- Freely accessible online immediately upon publication

- Authors retain the copyright to their work

- Licensing it under a Creative Commons license

- Visibility through different online platforms 